\section{FRI0429 NON TOPICAL PHARMACOLOGICAL TREATMENT OF EARLY, UNTREATED (DMARD-NAÏVE, SYSTEMIC THERAPY-NÄIVE) PSORIATIC DISEASE: A SYSTEMATIC REVIEW}

Gabriele De Marco ${ }^{1,2}$, Anna Berekméri ${ }^{1,2}$, Laura C. Coates ${ }^{3}$, Sayam Dubash ${ }^{1,2}$, Dafna D. Gladman ${ }^{4}$, Ennio Lubrano ${ }^{5}$, Dennis Mcgonagle ${ }^{1,2}$, Farrouq Mahmood ${ }^{2}$ Antonio Marchesoni ${ }^{6}$, Alexis Ogdie ${ }^{7}$, Miriam Wittmann ${ }^{1,2}$, Helena Marzo-Ortega ${ }^{1,2}$ Philip Helliwell ${ }^{1,2}$. ${ }^{1}$ University of Leeds, Leeds Institute of Rheumatic and Musculoskeletal Medicine, Leeds, United Kingdom; ${ }^{2}$ NIHR Leeds Biomedical Research Centre, Leeds, United Kingdom; ${ }^{3}$ University of Oxford, Nuffield Department of Orthopaedics, Rheumatology and Musculoskeletal Sciences, Oxford, United Kingdom; ${ }^{4}$ University of Toronto, Toronto Western Hospital and Krembil Research Institute, Toronto, Ontario, Canada; ${ }^{5}$ Università degli Studi del Molise, Dipartimento di Medicina e Scienze della Salute "Vincenzo Tiberio", Campobasso, Italy; ${ }^{6}$ ASST Gaetano Pini-CTO, Rheumatology, Milan, Italy, ${ }^{7}$ Perelman School of Medicine, University of Pennsylvania, Philadelphia, United States of America

Background: Psoriatic disease (PsD) refers to a systemic condition, probably driven by chronic and complex inflammatory mechanisms. PsD patients experience a fickle mixture of cutaneous (nail dystrophy, psoriatic lesions spectrum) and musculoskeletal (MSK: arthritis, enthesitis, dactylitis, spondylitis) inflammatory features, variously associated with other co-morbidities (ocular or bowel inflammatory disease, increased cardiovascular risk and metabolic syndrome).

Current evidence is limited in respect of the management of early, treatment-naïve PsD.

Objectives: To assess the literature with a focus on pharmacological interventions in early, treatment-naïve PsD.

Methods: Seven research questions were formulated according to the PICO approach: are interventions effective in obtaining control of overall PsD activity? Are interventions effective on peripheral arthritis? On dactylitis? On spondylitis? On enthesitis? On skin and nails?

The search was designed as a systematic review of the literature. Early PsD was defined as disease duration $\leq 2$ years, except for studies investigating outcomes restricted to the skin.

Criteria for including records were: adult human participants; participants with cutaneous features of PsD; participants with MSK features of PsD; double blind, single blind and non-blinded RCT; well-designed prospective studies/series.

The search protocol was registered on PROSPERO [1], the search was performed between June 2018 and January 2019.

Results: Resources available were widely explored (4 databases, 5 trial registers, 5 conference archives; see figure). The search retrieved 156,348 references (publication range 1946-2019) of which $308(0.2 \%)$ qualified for full-text-assessment (FTA, figure); 7 (0.0004\%) fulfilled the selection criteria and only 4 underwent data extraction.

\begin{tabular}{lccc}
\hline Ref. type & PsD feature targeted & Intervention (success) & Primary outcome \\
\hline 1 RCT & Skin & Secukinumab (yes) vs fumarates (no) & PASI75 \\
2 cohort & MSK & MTX part of T2T (yes) & Unclear \\
3 RCT & MSK & MTX (partial) & Joint count \\
4 RCT & Skin & Apremilast (yes) & PGAxBSA \\
\hline
\end{tabular}

Meta-analysis was impossible due to data heterogeneity (disease classification criteria, outcome measures and intervention durations). Although no clinical study adopted comprehensive composite indexes as primary outcome measures, $40 \%$ of FTA references described more than one component of PSD (i.e.: cutaneous and MSK) at least within the baseline characteristics. A substantial proportion of FTA references did describe, among participants recruited, many who were early untreated PsD at baseline. Unfortunately, separate analyses were not possible due to unavailability of the original datasets. A subset $(10 \%)$ of the FTA references did not report on the participants' exposure to previous treatment. Conclusion: Few studies addressed early, treatment naïve PsD. The underrepresentation of such data may be related to trial-enrolment criteria. More studies are needed to investigate this identified unmet need.

\section{REFERENCES:}

[1] http://www.crd.york.ac.uk/PROSPERO/display_record.php? ID=CRD42018097366

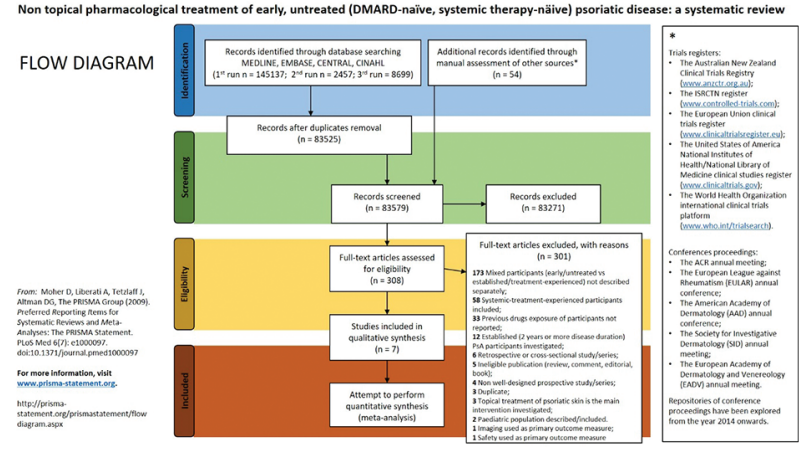

Figure

Acknowledgement: The authors wish to thank librarians J. Emmel and L. Mason for their support.

Disclosure of Interests: Gabriele De Marco: None declared, Anna Berek méri: None declared, Laura C Coates Grant/research support from: AbbVie, Celgene, Lilly, Novartis and Pfizer, Consultant for: AbbVie, Amgen, BMS, Celgene, Galapagos, Gilead Sciences Inc., Janssen, Lilly, Novartis, Pfizer, Prothena Corp and UCB, Sayam Dubash: None declared, Dafna D Gladman Grant/research support from: AbbVie, Amgen, Celgene, Lilly, Novartis, Pfizer, and UCB, Consultant for: AbbVie, Amgen, BMS, Celgene, Galapagos, Gilead, Janssen, Lilly, Novartis, Pfizer, and UCB, Ennio Lubrano Consultant for: Consultancy fees as speaker from Abbvie, Celgene, Novartis and Pfizer, Dennis McGonagle Consultant for: Lilly, Novartis UCB, Speakers bureau: Lilly, Novartis UCB, Farrouq Mahmood: None declared, Antonio Marchesoni Consultant for: honoraria from Abbvie, BSM, Celgene, Janssen, MSD, Novartis, Pfizer, UCB, Alexis Ogdie Grant/ research support from: (To my university) Novartis, Pfizer, Grant/research support from: Novartis, Pfizer, Grant/research support from: Novartis, Pfizer, Grant/research support from: Novartis, Pfizer, Consultant for: AbbVie, Bristol-Myers Squibb, Celgene, Corrona, Eli Lilly and Company, Novartis, Pfizer, and Takeda, Consultant for: AbbVie, Amgen, BristolMyers Squibb, Celgene, Corrona, Eli Lilly, Novartis, Pfizer Inc, Takeda, Consultant for: Abbvie, Amgen, BMS, Celgene, Corrona, Lilly, Novartis, Pfizer, Takeda, Consultant for: Abbvie, Amgen, BMS, Celgene, Corrona, Lilly, Novartis, Pfizer, Takeda, Miriam Wittmann Consultant for: consultancy honoraria from Abbvie, Celgene, Janssen, L'Oreal, Novartis and Pfizer, Helena Marzo-Ortega Grant/research support from: Janssen, Novartis and Pfizer, Consultant for: AbbVie, Celgene, Janssen, Eli-Lilly, Novartis and UCB, Speakers bureau: AbbVie, Celgene, Janssen, Eli-Lilly, Novartis and UCB, Philip Helliwell Grant/research support from: Paid to charity: from AbbVie, Janssen and Novartis, Consultant for: Paid to charity: from AbbVie, Amgen, Pfizer, and UCB and Celgene. Paid to self: from Celgene and Galapagos DOI: 10.1136/annrheumdis-2019-eular.1837

\section{FRI0430 \\ IXEKIZUMAB IMPROVES THE SIGNS AND SYMPTOMS OF PSORIATIC ARTHRITIS REGARDLESS OF SEX, DURATION OF DISEASE, OR BODY MASS INDEX IN TWO RANDOMIZED, PHASE 3 CLINICAL TRIALS}

Lihi Eder ${ }^{1}$, Satish Odhav ${ }^{2}$, Mariusz Korkosz ${ }^{3}$, Aubrey Trevelin Sprabery ${ }^{4}$, Amanda M. Gellett ${ }^{4}$, Chen-Yen Lin ${ }^{4}$, So Young Park ${ }^{4}$, Clinton C. Bertram ${ }^{4}$, Alexis Ogdie ${ }^{5}$. ${ }^{1}$ Women's College Hospital, Alberta, Canada; ${ }^{2}$ Arthritis Clinic, Jackson, United States of America; ${ }^{3}$ Jagiellonian University Medical College, Kraków, Poland; ${ }^{4}$ Eli Lilly and Company, Indianapolis, United States of America; ${ }^{5}$ Penn Medicine, Philadelphia, United States of America

Background: Ixekizumab (IXE) is a high-affinity monoclonal antibody that selectively targets interleukin-17A. During 24 weeks (wks) of treatment, IXE resulted in significantly greater improvements versus placebo (PBO) in the signs and symptoms of active psoriatic arthritis (PsA) in two randomized Phase 3 studies. $^{1,2}$

Objectives: To evaluate the consistency of clinical response with IXE in demographic subsets of patients (pts) with active PsA.

Methods: Clinical response to IXE was analyzed from an integrated database of 2 randomized, double-blind, Phase 3 studies in biologic Disease 